\title{
The Prevalence and Correlates of Fissured Tongue Among Outpatients in Andkhoy City, Afghanistan: A Cross-Sectional Study
}

\author{
Mohammad Hassan \\ Hamrah (D) ${ }^{1,2}$ \\ Ali Baghalian' \\ Sara Ghadimi ${ }^{\prime}$ \\ Saeedeh Mokhtari \\ Mojgan Kargar ${ }^{3}$ \\ Maryam Khosrozadeh' \\ Toba Dahi ${ }^{4}$ \\ Abdurrahman Charkazi ${ }^{5}$ \\ Mohammad Shoaib \\ Hamrah $\mathbb{1 D}^{6}$ \\ Mohammad Hussain \\ Hamrah $^{2}$ \\ 'Department of Paediatric Dentistry, \\ School of Dentistry, Tehran University of \\ Medical Sciences, Tehran, Iran; ${ }^{2}$ Curative \\ Clinic, Andkoy, Faryab, Afghanistan; \\ ${ }^{3}$ Department of Paediatric Dentistry, \\ School of Dentistry, Shahid Sadoughi \\ University of Medical Sciences, Yazd, Iran; \\ ${ }^{4}$ Abant Izzet Baysal University Faculty of \\ Dentistry, Bolu, Turkey; ${ }^{5}$ Health \\ Education and Promotion, Environmental \\ Health Research Center, Faculty of \\ Health, Golestan University of Medical \\ Sciences, Gorgan, Iran; ${ }^{6}$ Shaheed Ostad \\ Esmail”Aslam" Aimaq Hospital, \\ Anadkhoy, Faryab Province, Afghanistan
}

Correspondence: Mohammad Hussain Hamrah

Curative Clinic Andkhoy, Amir Timor Street, Shari now, Andkhoy, Afghanistan Email hkmul99l@gmail.com
Background: Fissured tongue is a common manifestation of the tongue, marked by the presence of multiple prominent grooves or fissures on the dorsal surface of the tongue. However, there is a lack of studies focusing on the prevalence and factors associated with fissured tongue among patients attending an outpatient clinic in Afghanistan.

Aim: The purpose of the current study was to determine the prevalence and factors associated with fissured tongue and its effects on the general health of adult outpatients in Afghanistan.

Patients and Methods: The cross-sectional survey was conducted among outpatient populations in Andkhoy City, Afghanistan, between September 2019 and December 2019. A convenience technique was applied by including 1182 patient aged 18-80 years. Socio-economic status, smoking, nass use (smokeless tobacco use) and medical data were collected using face-toface interviews. We used logistic regression analysis to identify factors associated with fissured tongue. A convenience technique was applied by including patient aged 18-80 years.

Results: The studied population consisted of 1182 participants, of whom 573 (48.5\%) were males and 609 (51.5\%) females. The prevalence of fissured tongue was $27.2 \%$ (95\% CI: $24.7-29.9 \%)$ with males having significantly higher prevalence than females $(47.5 \%, 95 \%$ CI: $43.3-51.6 \%$ versus $8.2 \%, 95 \%$ CI: $6.2-10.7 \%, \mathrm{p}<0.001)$. Male participants (OR=7.1, 95\% CI: 4.8-10.3), diabetes mellitus (OR=1.6, 95\% CI: $1.1-2.3)$ and smokeless tobacco use $(\mathrm{OR}=12.0,95 \% \mathrm{CI}: 8.1-17.6)$ were the only variables independently associated with fissured tongue.

Conclusion: This study suggested that there was a high rate of fissured tongue among an outpatient clinic in Andkhoy, Afghanistan. Male gender, diabetes mellitus, and nass consumption were associated with fissured tongue. Therefore, these factors might usefully be targeted in local health promotion, prevention and early intervention programs.

Keywords: fissured tongue, prevalence, risk factors, Andkhoy, Afghanistan

\section{Introduction}

The tongue is the body's most complex structure and considered the most important muscular organ in the mouth. ${ }^{1}$ The tongue has many functions, including taste, phonation, swallowing, breathing, speaking and chewing. ${ }^{2}$ Systemic disease may first present with tongue pathology or alterations in the tongue which can then lead to numerous systemic diseases. ${ }^{3}$ There are variations in the presentation and frequency of oral manifestation of systemic diseases. The number of people with oral manifestations of systemic diseases has been predicted to increase. ${ }^{4}$ The elderly are likely to have various manifestations associated with systemic diseases, that could affect the oral health care. ${ }^{5}$ 
Fissured tongue, or scrotal tongue or lingua plicata, is a common manifestation of the tongue which is distinguished by a deep, prominent groove on the dorsum of the tongue. ${ }^{6}$ Fissures on the tongue vary in depth and can be shallow or deep. A cracked tongue can trap food, it can lead to localized inflammation, a burning sensation of the tongue and bad breath. ${ }^{7,8}$

Diagnosis can best be made through oral examination and personal history. ${ }^{9}$ The prevalence of fissured tongue varies across the country, generally affecting between $10 \%$ and $48.4 \%$ of the population. ${ }^{10-14}$ Previous studies have shown that fissured tongue is correlated to inheritance, candidiasis, the use of smokeless tobacco (in Afghanistan smokeless tobacco is known as nass) and systemic diseases including hypertension, psoriasis, orofacial granulomatosis and diabetes mellitus (DM). ${ }^{15-18}$

There is a paucity of data relating to the prevalence and factors associated with fissured tongue among Afghan adults living in Afghanistan. A point to consider is the access to health services which is particularly poor in parts of rural Afghanistan. ${ }^{19}$ This study was conducted to highlight the impact of limited access to health services in these areas. The aim of this study was to determine the prevalence and factors associated with fissured tongue among patients visiting an outpatient clinic in Andkhoy, Afghanistan.

\section{Patients and Methods Study Population and Setting}

The cross-sectional survey was conducted among outpatient populations in Andkhoy, a city in the northern part of Afghanistan. Andkhoy is a district in the Faryab Province of north-western Afghanistan with an approximate population of 37,100 . The district is located in the northern part of the province. ${ }^{20}$ This clinic is an outpatient service for people who need to see a specialist, and it provides patients with care, ongoing management and referrals to other services, if needed. The clinic is also a referral centre in Faryab province in the northern part of Afghanistan.

\section{Study Design and Period}

A convenience technique was applied by including patient aged 18-80 years. The cross-sectional survey was conducted among outpatient populations in Andkhoy city, Afghanistan, between September 2019 and December 2019.

\section{Sample Size Determination}

The study samples from permanent residents of Andkhoy district. Data was obtained from 1182 patients. Due to the unavailability of previous estimate of prevalence of the correlates of fissured tongue among outpatients in Andkhoy city and considering the prevalence of fissured tongue and their associated factors in similar setting, the number of subjects is due to be 600 , and after taking into account the design effect ( $\mathrm{DE}=2$ ) of cluster sampling, the final sample size is expected to reach to 1200 which is reasonable for achieving study objectives. This study was conducted in accordance with the Declaration of Helsinki.

\section{Data Collection Tools and Techniques}

Surveys were conducted by interviewers face-to-face using the WHO STEP-wise questionnaire. ${ }^{21}$

The clinical examinations were performed by the trained doctors. Patients with limited mouth opening and patients who were unable to protrude the tongue were excluded from the study.

\section{Validity and Reliability}

Translation involved translating the English questionnaires into Dari (target language) by independent bilingual translators. Additionally, the Persian version of the WHO STEP-wise questionnaire was used, and the questionnaire has been validated. ${ }^{22}$ Persian and Dari are mutually intelligible varieties of the same language. The questionnaire was also tested on thirty patients to examine its utility and effectiveness. Clarifications were made in questions where needed (the sample used in the pilot study was not included in the main study).

\section{Data Collection Procedure}

Informed consent was received from all patients, and they were advised that their participation was voluntary and anonymous. The study was approved by the Faryab Public Health Directorate, Afghanistan. The study assessed socio-demographic variables including age, gender, education, job, and tobacco use (cigarette smoking and nass use). Questions were asked about the patients' tongue symptoms associated with systemic diseases such as tongue burning. Patients were assessed with a comprehensive history and physical examination. While in a seated position, the patients were assessed using a straight probe, a light and a mouth mirror. The examination of the oral cavity was performed using sterile gloves, sterile gauze and wooden tongue depressor. The 
patients were asked to protrude the tongue and to perform maximal mouth opening. No biopsy was performed. Classification of fissured tongue was assigned according to the pattern of the fissure. Patients with a fissured tongue were classified into the following types in accordance with pattern of tongue fissures. a. Central longitudinal pattern, b. Central transverse pattern, c. Lateral longitudinal pattern, d. Branching pattern, and e. Diffuse pattern. ${ }^{18}$ The participants were divided into four groups according to their smoking status: current smokers, past smokers, and non-smokers. Current smokers were defined as patients who have smoked at least 100 cigarettes in their entire life and have smoked during the past 30 days. Past smokers were defined as patients that have smoked at least 100 cigarettes in their entire life and but have not smoked during the past 30 days. Non-smokers were defined as patients who have never smoked a cigarette or had smoked less than 100 cigarettes in their lifetime. Since the number of past smokers was very low, past smokers and never smokers were considered in the non-smokers group in this study. ${ }^{23}$ Nass' is a smokeless tobacco product widely used in Afghanistan, Iran, Pakistan and the Central Asian Republics. Nass consists of tobacco leaves, lime, cotton oil or sesame oil, and ash. Nass is consumed by placing it in the mouth cavity, usually between the oral mucosa and gingival cavity or sometimes under the tongue. ${ }^{24}$ Patients were classified into four categories according to their nass use: non-nass users, past nass users, and current nass users. Non-nass users were defined as patients that have not used nass in their lifetime. Past nass users were defined as patients that have quit nass use at least one month ago. Current nass users were defined as patients who have not used nass more than 20 times in their lives and use nass every day or only occasionally (Note from J: I wasnt sure what you meant here, so I am just guessing). ${ }^{25}$ Since the number of past smokers was very low, both past nass users and never nass users were constituted in the non-nass user's category.

Hypertension was defined as a blood pressure at or above $140 / 90 \mathrm{~mm} \mathrm{Hg}$ on two separate measurements or are taking medications for hypertension. ${ }^{26} \mathrm{DM}$ (diabetes mellitus): A fasting blood glucose $\geq 126 \mathrm{mg} / \mathrm{dL}$, or a random blood glucose level of $\geq 200 \mathrm{mg} / \mathrm{dL}$, or on the treatment of antidiabetic drugs therapy. ${ }^{27}$

\section{Data Analysis}

Statistical analysis was performed using SPSS software ver. 22.0 (IBM, Armonk, NY, USA). A descriptive analysis was conducted on participant characteristics using frequencies, means, \pm standard deviation (SD) and 95\% CI (confidence interval). Chi-square tests were done to investigate the associations between fissured tongue and socio-demographic variables, include, age, sex, education, occupation, tobacco use (cigarette smoking and nass use); systemic diseases, namely, hypertension and DM. Univariate associations between fissured tongue and each of the above-mentioned variable variables were first assessed using a series of univariate logistic regression analyses. All variables that might be a risk factor or might lead to fissured tongue were considered as the independent variables including sex, age groups, education level, marital status, occupation, smoking, nass use, hypertension and DM. Any variable was significantly associated with fissured tongue in the univariate logistic regression analysis were selected as a candidate for the multivariate analysis. $P$ value of $<0.05$ was considered statistically significant.

\section{Results}

The studied population consisted of 1182 patients, of whom $573(48.5 \%)$ were males and 609 (51.5\%) females. The overall prevalence of fissured tongue among participants was $27.2 \%$ (95\% CI: 24.7-29.9\%), with males having significantly higher prevalence than females $(47.5 \%, 95 \%$ CI: $43.3-51.6 \%$ versus $8.2 \%, 95 \%$ CI: $6.2-10.7 \%, p<0.001)$. Participants with fissured tongue had significantly higher levels of nass use than those without fissured tongue $(68.2 \%$ versus $12.8 \%, p<0.001)$. The fissured tongue was significantly higher among participants who were smokers $(44.8 \%$ versus $21.8 \%, p<0.001)$. Participants with a fissured tongue had higher levels of hypertension (33.0\%), and DM (42.1\%\%) than those who did not. Fissured tongue was common among participants with other types of jobs $(38.3 \%)$

Table 1 shows the socio-demographic and related characteristics of the participants.

Most participants with fissured tongue were asymptomatic. In our study, the most common type of fissured tongue was the central longitudinal pattern $(42.9 \%)$, whereas the lateral longitudinal pattern was the least tongue fissured type in the study sample (8.4\%). The distribution patterns of fissured tongue in our study is shown in (Figure 1).

Table 2 indicates the results from a multivariate logistic regression analysis of the associations between fissured tongue, sex, occupation, smoking, nass use, DM, and hypertension. The likelihood of having fissured tongue was 7.1 times higher among male participants than those of female participants (95\% CI: 4.8-10.3). Nass users (OR, $12.095 \%$ CI: 8.1-17.6), and DM (OR 1.6, 95\% CI: 1.1-2.3), were also found to have higher odds to have fissured tongue. 
Table I Socio-Demographic and Clinical Variables of Patients with and without Fissured Tongue

\begin{tabular}{|c|c|c|c|}
\hline Variables & $\begin{array}{l}\text { With FT } \\
(n=322)\end{array}$ & $\begin{array}{l}\text { Without FT } \\
(n=860)\end{array}$ & $p$-value \\
\hline \multicolumn{4}{|l|}{ Gender, no (\%) } \\
\hline Male & $272(84.5)$ & $301(35.0)$ & $<0.001$ \\
\hline Female & $50(15.5)$ & $559(65.0)$ & \\
\hline Age (in years) number, no (\%) & & & 0.072 \\
\hline$<39$ & $28(8.7)$ & $68(7.9)$ & \\
\hline $40-49$ & $28(8.7)$ & $124(14.4)$ & \\
\hline $50-59$ & $94(29.2)$ & $244(28.4)$ & \\
\hline$\geq 60$ & $172(53.4)$ & $424(49.3)$ & \\
\hline Level of education, no (\%) & & & 0.062 \\
\hline Illiterate & $117(36.3)$ & $278(32.3)$ & \\
\hline Primary/private education & $50(15.5)$ & $122(14.2)$ & \\
\hline Secondary & $91(28.3)$ & $223(25.9)$ & \\
\hline High school or more & $64(19.9)$ & $237(27.6)$ & \\
\hline Marital status, no (\%) & & & 0.258 \\
\hline Single & $16(5.0)$ & $64(7.4)$ & \\
\hline Married & $276(85.7)$ & $728(84.7)$ & \\
\hline Others & $30(9.3)$ & $68(7.9)$ & \\
\hline Occupation, no (\%) & & & 0.003 \\
\hline Employed & $36(11.2)$ & $158(18.4)$ & \\
\hline Unemployed & II 4 (35.4) & $260(30.2)$ & \\
\hline Farmer & II (3.4) & $19(2.2)$ & \\
\hline Housewife & $130(40.4)$ & $373(43.4)$ & \\
\hline Other types of jobs & $31(9.6)$ & $31(9.6)$ & \\
\hline Nass use, no (\%) & & & $<0.001$ \\
\hline Yes & $210(65.2)$ & $98(11.4)$ & \\
\hline No & II $2(34.8)$ & $762(88.6)$ & \\
\hline Smoking, no (\%) & & & $<0.001$ \\
\hline Yes & $126(39.1)$ & $155(18.0)$ & \\
\hline No & $196(60.9)$ & $705(82.0)$ & \\
\hline Hypertension, n (\%) & & & $<0.001$ \\
\hline Yes & I 44 (44.7) & $292(34.0)$ & \\
\hline No & $178(55.3)$ & $568(66.0)$ & \\
\hline Diabetes mellitus, n (\%) & & & 0.001 \\
\hline Yes & $120(37.3)$ & 165 (19.2) & \\
\hline No & $202(62.7)$ & $695(80.8)$ & \\
\hline
\end{tabular}

Abbreviation: FT, fissured tongue.

\section{Discussion}

It is worthy to note that this is the first study to investigate the prevalence and factors associated with fissured tongue among outpatients in Andkhoy City, Afghanistan. The findings suggest that fissured tongue is common in this population, with more than one quarter $(27.2 \%)$ patients having fissured tongue. The findings of our study suggested that the prevalence of fissured tongue was high among outpatients in Afghanistan, with males having a significantly higher prevalence than females, and were also associated with housewives, nass users, non-smokers, hypertensive and diabetic patients. In multivariate analysis, male gender, DM, and nass use were the variables most strongly associated with fissured tongue. 


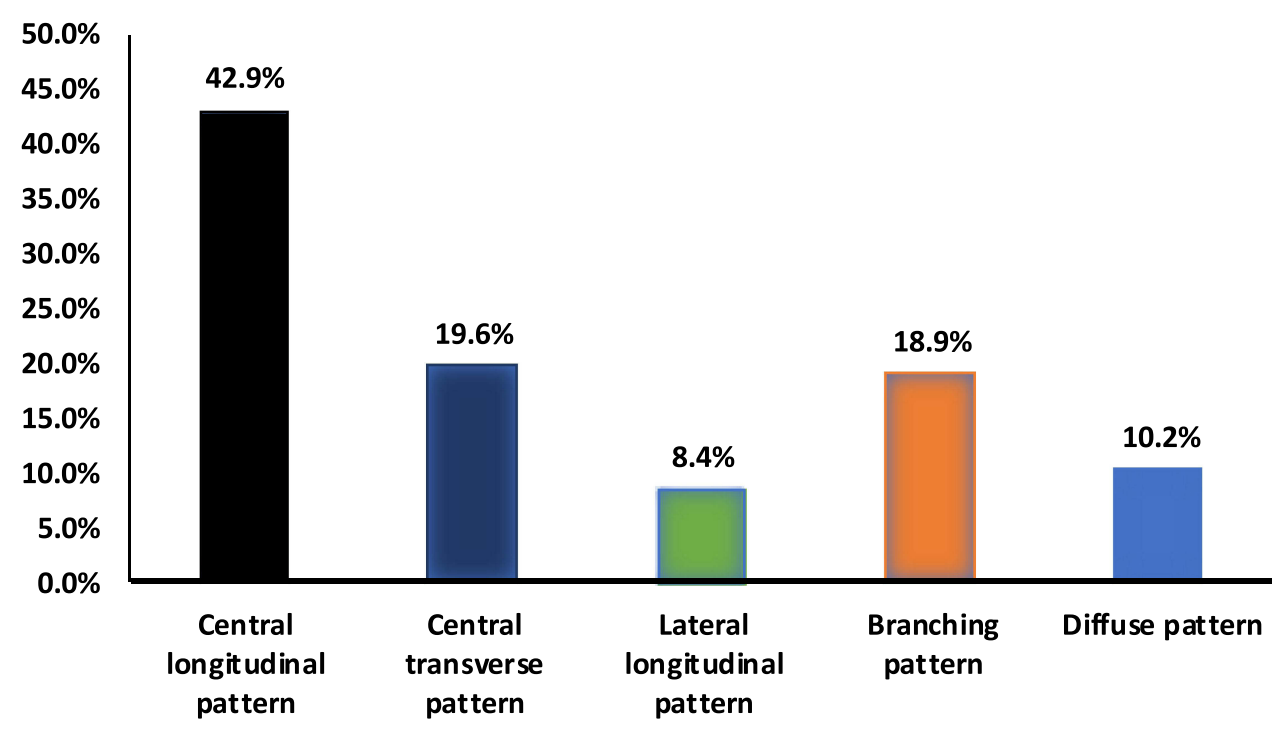

Figure I The distribution patterns of fissured tongue among study participants.

Among patients attending the outpatient clinic in Andkhoy, Afghanistan, fissured tongue was found in $(27.2 \%)$ of the total sample. This finding is lower than previous research conducted among patients in the department of Oral Medicine and Oral Diagnosis at the Faculty of Dentistry, Benghazi Libya (48.4\%). ${ }^{14}$ However, the

Table 2 Multivariate Logistic Regression Analysis of Variables Correlated to with Fissured Tongue Among Study Sample

\begin{tabular}{|c|c|c|c|c|}
\hline Variables & $\begin{array}{l}\text { Fissured Tongue } \\
\mathrm{N}=322\end{array}$ & OR & $(95 \% \mathrm{CI})$ & $P$ value \\
\hline $\begin{array}{l}\text { Gender, n (\%) } \\
\text { Female } \\
\text { Male }\end{array}$ & $\begin{array}{l}272(84.5) \\
50(15.5)\end{array}$ & $\begin{array}{l}1 \\
7.1\end{array}$ & $4.8-10.3$ & $<0.001$ \\
\hline $\begin{array}{l}\text { Occupation, no (\%) } \\
\text { Employed } \\
\text { Unemployed } \\
\text { Farmer } \\
\text { Housewife } \\
\text { Other }\end{array}$ & $\begin{array}{l}\text { I I } 4(35.4) \\
\text { II (3.4) } \\
\text { I } 30(40.4) \\
3 \text { I (9.6) }\end{array}$ & $\begin{array}{l}1.0 \\
0.92 \\
0.66 \\
1.0 \\
1.7\end{array}$ & $\begin{array}{l}0.53-1.6 \\
0.22-1.9 \\
0.6-1.8 \\
0.80-3.8\end{array}$ & $\begin{array}{l}0.754 \\
0.477 \\
0.887 \\
0.164\end{array}$ \\
\hline $\begin{array}{l}\text { Nass use, n (\%) } \\
\text { No } \\
\text { Yes }\end{array}$ & $\begin{array}{l}210(65.2) \\
112(34.8)\end{array}$ & $\begin{array}{l}0.91 \\
1 \\
12.0\end{array}$ & $\begin{array}{l}0.4-2.2 \\
8.1-17.6\end{array}$ & $\begin{array}{l}0.843 \\
<0.001\end{array}$ \\
\hline $\begin{array}{l}\text { Hypertension, n (\%) } \\
\text { No } \\
\text { Yes }\end{array}$ & $\begin{array}{l}\text { I } 44(44.7) \\
\text { I } 78(55.3)\end{array}$ & 1.3 & $0.90-1.87$ & 0.159 \\
\hline $\begin{array}{l}\text { Diabetes mellitus, n (\%) } \\
\text { No } \\
\text { Yes }\end{array}$ & $\begin{array}{l}120(37.3) \\
202(62.7)\end{array}$ & $\begin{array}{l}1 \\
1.6\end{array}$ & I.I-2.3 & 0.02 \\
\hline $\begin{array}{l}\text { Smoking, n (\%) } \\
\text { Yes } \\
\text { No }\end{array}$ & $\begin{array}{l}126(39.1) \\
196(60.9)\end{array}$ & $\begin{array}{l}1 \\
0.91\end{array}$ & $0.61-1.35$ & 0.641 \\
\hline
\end{tabular}

Note: $P$ value of $<0.05$ was considered statistically significant.

Abbreviations: OR, odds ratio; $\mathrm{Cl}$, confidence interval. 
results of this study showed that the prevalence of fissured tongue was higher than that found in patients attending the Department of Oral Medicine and Radiology, Jodhpur Dental College General Hospital in India $(14.9 \%){ }^{13}$ Differences in the rates of fissured tongue could be attributable to variations in the characteristics of participants, race, and ethnicity in the studies sampled.

In this study, we found that the smoking prevalence of fissured tongue was higher among men than women. A similar finding has been reported in another study among outpatients in India. ${ }^{13,28}$ However, the opposite pattern is seen for Indian and Brazilian outpatients. ${ }^{10,29}$ Our findings support the hypothesis that males encountered a higher burden of fissured tongue compared to females. A possible explanation for the preponderance of fissured tongue among males in our study can be explained by the higher prevalence of nass use by males, whereas because of cultural constraints, females are less likely to use nass. Of the 1182 study population examined, 230 male participants had a habit of nass use, while 78 females were recorded as nass users, and participants with fissured tongue had significantly higher levels of nass use than those without fissured tongue.

In multivariate analysis nass use was the variable most strongly associated with fissured tongue comparable to previous studies in the Southwest of Sweden. ${ }^{16}$ It is believed that SLT (smokeless tobacco), may result in oral tissue changes due to local irritation effect among SLT users. This could be attributed to injury to the oral epithelium caused by SLT products and their ingredients. ${ }^{30} \mathrm{~A}$ previous study has found that a high risk of cancer is linked to the toxic chemicals in nass. ${ }^{31}$ Nass causes local tissue trauma in the mouth, throat and tongue by erosion. ${ }^{32}$ Saeed et al has shown that high degree of toxic heavy metals could be attributed to using ashes and lime in nass. ${ }^{31}$ These findings suggest that there is a correlation between nass use and fissured tongue. This implies it may be a possible to decrease the harmful effects of nass use by helping patients to quit using nass.

The study shows that diabetes is an independent risk factor for fissured tongue. These findings are comparable to the results of studies among outpatients in India and Pakistan. ${ }^{33,34}$ An illustration of the relationship between diabetes and fissured tongue could be inadequate blood glucose control, immunological changes, microcirculatory alternation with decrease of blood flow, xerostomia and alteration in salivary flow and composition. ${ }^{33,35,36}$

\section{Limitations}

Overall, the current study has some limitations: Firstly, it is a single centre study, which limits the possibility of generalizing to all the people in Afghanistan. Secondly, the sample was non-random which may affect its overall power. Furthermore, the sample was selected using convenience sampling which limited the generalizability of the results. Finally, cross-sectional studies cannot be used to determine causal relationships with risk factors associated with fissured tongue. One of the strengths of this study is that it can be valuable for the accumulation of further data on the prevalence of fissured tongue and studies of variables potentially correlated to fissured tongue in Afghanistan. Additionally, study populations could be replicated in other study.

\section{Conclusions}

In conclusion, the study revealed a high prevalence of fissured tongue in an outpatient clinic in Andkhoy, Afghanistan with males having significantly higher prevalence than females. This study has found that being of male gender, DM and nass consumption were most important determinates of fissured tongue among an outpatient clinic in Afghanistan. This study suggests that for oral health promotion and illness prevention there is urgent need for an early intervention program particularly these targeting factors.

\section{Data Sharing Statement}

Research data not shared.

\section{Acknowledgments}

Our study project was supported by the Terumo Life Science Foundation.

\section{Disclosure}

The authors report no conflicts of interest in this work.

\section{References}

1. Bai YD, Sathasivasubramanian Sankarapandian RA. A wide spread red lesion on the surface of the tongue-a case report and review of differential diagnosis. J Clin Diagn Res. 2017;11(6):ZD07.

2. Cymrot M, de Assis F, Teixeira A, Sales FCD, Neto FJ. Subtotal glossectomy by modified keyhole lingual resection technique for the treatment of true macroglossia: glossectomia subtotal pela técnica de ressecção lingual em orifício de fechadura modificada como tratamento de macroglossia verdadeira. Revista Brasileira De Cirurgia Plástica. 2012;27(1):165-169. doi:10.1590/S1983-5175201200 0100028 
3. Bordoni B, Morabito B, Mitrano R, Simonelli M, Toccafondi A. The anatomical relationships of the tongue with the body system. Cureus. 2018;10(12):e3695. doi:10.7759/cureus.3695

4. Porter S, Mercadente V, Fedele S. Oral manifestations of systemic disease. BDJ Team. 2018;5(1):18012. doi:10.1038/bdjteam.2018.12

5. Scully C, Ettinger RL. The influence of systemic diseases on oral health care in older adults. J Am Dent Assoc. 2007;138:S7-S14. doi:10.14219/jada.archive.2007.0359

6. Yarom N, Cantony U, Gorsky M. Prevalence of fissured tongue, geographic tongue and median rhomboid glossitis among Israeli adults of different ethnic origins. Dermatology. 2004;209(2):88-94 doi:10.1159/000079590

7. Gnanapragasam V. Fissured tongue vs geographic tongue. Independent Nurse. 2007;2007(9). doi:10.12968/indn.2007.1.9. 75207

8. Gonzaga HF, Oliveira LR, Picciani BLS, et al. Investigation of the psychological factors associated with fissured tongue. Revista Gaúcha De Odontologia. 2019;67:e20190017. doi:10.1590/198186372019000173559

9. Al-Maweri S-A, Tarakji B, Al-Sufyani GA, Al-Shamiri HM, Gazal G. Lip and oral lesions in children with down syndrome. A controlled study. J Clin Exp Dent. 2015;7(2):e284. doi:10.4317/jced.52283

10. Darwazeh A, Almelaih -A-A. Tongue lesions in a Jordanian population. Prevalence, symptoms, subject's knowledge and treatment provided. Med Oral Patol Oral Cir Bucal. 2011;16(6):e745-e749. doi:10.4317/medoral.17098

11. Gönül M, Gül Ü, Kaya İ, et al. Smoking, alcohol consumption and denture use in patients with oral mucosal lesions. J Dermatol Case Rep. 2011;5(4):64. doi:10.3315/jdcr.2011.1079

12. Jahanbani J, Sandvik L, Lyberg T, Ahlfors E. Evaluation of oral mucosal lesions in 598 referred Iranian patients. Open Dent J. 2009;3:42. doi:10.2174/1874210600903010042

13. Patil S, Kaswan S, Rahman F, Doni B. Prevalence of tongue lesions in the Indian population. J Clin Exp Dent. 2013;5(3):e128. doi:10.4317/jced.51102

14. Byahatti SM, Ingafou MS. The prevalence of tongue lesions in Libyan adult patients. 2010.

15. Guggenheimer J, Moore PA, Rossie K, et al. Insulin-dependent diabetes mellitus and oral soft tissue pathologies. II. Prevalence and characteristics of Candida and candidal lesions. Oral Surg Oral Med Oral Pathol Oral Radiol Endodontol. 2000;89(5):570-576. doi:10.1067/moe.2000.104477

16. Dafar A, Çevik-aras H, Robledo-Sierra J, Mattsson U, Jontell M. Factors associated with geographic tongue and fissured tongue. Acta Odontol Scand. 2016;74(3):210-216. doi:10.3109/ 00016357.2015 .1087046

17. Al-Maweri SA, Alaizari NA, Al-Sufyani GA. Oral mucosal lesions and their association with tobacco use and qat chewing among Yemeni dental patients. J Clin Exp Dent. 2014;6(5):e460. doi: $10.4317 /$ jced 51706

18. Sudarshan R, Sree Vijayabala G, Samata Y, Ravikiran A. Newer classification system for fissured tongue: an epidemiological approach. J Trop Med. 2015;2015:262079. doi:10.1155/2015/262079

19. Kim C, Saeed KMA, Salehi AS, Zeng W. An equity analysis of utilization of health services in Afghanistan using a national household survey. BMC Public Health. 2016;16(1):1226. doi:10.1186/ s12889-016-3894-z

20. Wikipedia. Andkhoy 2020; 2021. Available from: https://en.wikipe dia.org/wiki/Andkhoy\#cite_note-EB1911-2. Accessed July 16, 2021.
21. WHO. STEPwise Approach to Noncommunicable Disease Risk Factor Surveillance (STEPS) 2016. WHO; 2016.

22. Delavari A, Alikhani S, Alaedini F. A National Profile of NonCommunicable Disease Risk Factors in the IR of Iran. Ministry of Health, Deputy to Health Directory, CDC; 2005.

23. Lim HK, Ghazali SM, Kee CC, et al. Epidemiology of smoking among Malaysian adult males: prevalence and associated factors. BMC Public Health. 2013;13(1):8. doi:10.1186/1471-2458-13-8

24. Hamrah MS, Hamrah MH, Dahi T, et al. Nass use and associated factors among outpatients in northern Afghanistan: a cross-sectional study in Andkhoy City. Tob Induc Dis. 2018;16:36. doi:10.18332/tid/ 93574

25. Nelson DE, Mowery P, Tomar S, Marcus S, Giovino G, Zhao L. Trends in smokeless tobacco use among adults and adolescents in the United States. Am J Public Health. 2006;96(5):897-905. doi:10.2105/AJPH.2004.061580

26. James PA, Oparil S, Carter BL, et al. 2014 evidence-based guideline for the management of high blood pressure in adults: report from the panel members appointed to the Eighth Joint National Committee (JNC 8). JAMA. 2014;311(5):507-520. doi:10.1001/ jama.2013.284427

27. American Diabetes Association. Standards of medical care in diabetes-2014. Diabetes Care. 2014;37:S14. doi:10.2337/dc14-S014

28. Mathew A, Cherian S, Daniel M, Abraham T, Mathew R. Prevalence of fissured tongue in a South Indian population-A cross-sectional study. J Oral Med. 2017;1(1):9.

29. Vieira-Andrade RG, Guimarães Z, de Faria F, et al. Oral mucosa alterations in a socioeconomically deprived region: prevalence and associated factors. Braz Oral Res. 2011;25(5):393-400. doi:10.1590/ S1806-83242011000500004

30. Aljabab MA, Aljbab AA, Patil SR. Evaluation of oral changes among tobacco users of Aljouf Province, Saudi Arabia. J Clin Diagn Res. 2015;9(5):ZC58.

31. Saeed M, Muhammad N, Khan SA, et al. Assessment of potential toxicity of a smokeless tobacco product (naswar) available on the Pakistani market. Tob Control. 2012;21(4):396-401. doi:10.1136/ tc. 2010.042630

32. Baig S, Rubab Z, Arif MM, Lucky M. Chewable risk factors-threatened oral cancer HPV's looming epidemic in Pakistan. Eur J Biotechnol Biosci. 2015;3(1):39-45.

33. Dikshit RP, Ramadas K, Hashibe M, Thomas G, Somanathan T, Sankaranarayanan R. Association between diabetes mellitus and pre-malignant oral diseases: a cross sectional study in Kerala, India. Int $J$ Cancer. 2006;118(2):453-457. doi:10.1002/ijc.21345

34. Mohsin SF, Ahmed SA, Fawwad A, Basit A. Prevalence of oral mucosal alterations in type 2 diabetes mellitus patients attending a diabetic center. Pak J Med Sci. 2014;30(4):716. doi:10.12669/ pjms.304.5220

35. Cicmil S, Mladenović I, Krunić J, Ivanović D, Stojanović N. Oral alterations in diabetes mellitus. Balkan J Dent Med. 2018;22(1):7-14. doi:10.2478/bjdm-2018-0002

36. Bastos AS, Leite AR, Spin-Neto R, Nassar PO, Massucato EM, Orrico SR. Diabetes mellitus and oral mucosa alterations: prevalence and risk factors. Diabetes Res Clin Pract. 2011;92(1):100-105. doi:10.1016/j.diabres.2011.01.011 


\section{Publish your work in this journal}

Clinical, Cosmetic and Investigational Dentistry is an international, peer-reviewed, open access, online journal focusing on the latest clinical and experimental research in dentistry with specific emphasis on cosmetic interventions. Innovative developments in dental materials, techniques and devices that improve outcomes and patient satisfaction and preference will be highlighted. The manuscript management system is completely online and includes a very quick and fair peer-review system, which is all easy to use. Visit http://www.dovepress.com/testimonials.php to read real quotes from published authors. 